\title{
A VALORIZAÇÃO DAS CULTURAS INFANTIS ATRAVÉS DAS BRINCADEIRAS IMAGINATIVAS
}

\author{
Susana Angelin Furlan', Denise Watanabe ${ }^{1}$, Nathália Franco Alves ${ }^{2}$, José Milton de Lima ${ }^{3}$ \\ Universidade Estadual Paulista - UNESP. ${ }^{1}$ Mestrado em Educação, ${ }^{2}$ Licenciatura em Educação Física, ${ }^{3}$ Departamento de \\ Educação, Presidente Prudente, SP. E-mail: susanaangelin20@gmail.com. Agência de Fomento: PIBIC/CNPq
}

\section{RESUMO}

Este artigo é um recorte de uma pesquisa de Iniciação Científica (IC), cujo título "No mundo da criança: resgatando a fantasia do real no contexto da Educação Infantil", teve início em 2011 em algumas salas de Educação Infantil de uma escola no interior paulista, ao constatar que havia uma carência de saberes referentes à imaginação infantil. A partir desse fato, buscou-se estimular e ampliar a imaginação infantil por vezes latente - por meio de brincadeiras; de músicas; de representações; de personagens imaginários (Lipe e Luci) e de brinquedos. Fundamentada na Sociologia da Infância, a pesquisa adotou a abordagem de natureza qualitativa e a metodologia da pesquisa-intervenção, com vistas a levantar reflexões teóricas e práticas que colaborassem com transformações na realidade. Como resultados, destacam-se: maior expressão imaginativa das crianças e efetiva participação das professoras - em todas as brincadeiras e atividades propostas pelos pesquisadores bolsistas.

Palavras-chave: Criança; Imaginação; Brincadeiras; Infância; Sociologia da infância.

\section{THE ENHANCEMENT OF CHILDREN'S CULTURES THROUGH IMAGINATIVE PLAY.}

\section{ABSTRACT}

This article is a clipping of a survey of scientific initiation (IC), whose title "in the world of the child: rescuing the real fantasy in the context of early childhood education", began in 2011 in some early childhood classrooms of a school in the State of São Paulo, to find that there was a lack of knowledge regarding children's imagination. From that fact, sought to stimulate and expand children's imaginations-sometimes latent-through games; of songs; of representations; of imaginary characters (Lipe and Luci) and toys. Based on the Sociology of childhood, the research adopted the approach of qualitative nature and methodology of intervention research, with a view to raising the theoretical and practical reflections that collaborate with changes in reality. As a result, include: greater imaginative expression of children and effective participation of teachers in all the games and activities proposed by researchers scholars.

Keywords: Child; Imagination; Jokes; Childhood; Sociology of childhood.

\section{INTRODUÇÃO}

Desde o nascimento (sem olvidar o ventre materno), a criança está exposta e em contato com o mundo, com sons, com cores, com cheiros, com sensações, com pessoas, com objetos e com situações diversas. O suprimento das necessidades biofisiológicas dos bebês, os cuidados, os estímulos e as interações permitem seu crescimento e desenvolvimento gradativo. Ao adentrar o espaço das creches e escolas de Educação Infantil, portanto, compreende-se que as crianças já possuem uma bagagem de experiências (culturais, históricas, sociais, relacionais, estruturais, econômicas, afetivas, entre outras) construídas e influenciadas pela vivência com familiares, com vizinhos, com amigos e com pessoas próximas, aos quais tiveram contato anteriormente. Dessa forma, ao ingressar nas creches e nas escolas de Educação Infantil, as crianças já participam e expressam suas culturas infantis. Nesses espaços, elas ampliam o rol de relações, ao [...] "produzir e a participar de uma série de cultura de pares" (CORSARO, 2011 p. 38).

As creches e as escolas constituem espaço privilegiado de diversidade cultural, de conhecimentos e linguagens, de possibilidades, de vivências, de experiências, de relações sociais 
com educadores, professores, funcionários e, principalmente, com seus pares infantis. Portanto, além do cuidar e do educar, é fonte do novo.

As brincadeiras também estão presentes, seja em casa ou na escola, são fundamentais para as crianças e, embora os adultos também brinquem, constitui-se aquilo que as crianças fazem de mais significativo e sério (SARMENTO, 2003). As brincadeiras estão presentes em documentos importantes como o Referencial Curricular Nacional da Educação Infantil (RCNEI, 1998), as Diretrizes Curriculares Nacionais para a Educação Infantil (DCNEI, 2010), o Manual de Brinquedos e Brincadeiras de Creches (2012), entre outros.

Entretanto, a brincadeira não é inata na criança, mas algo que precisa ser ensinado, aprendido, (re) criado. Cabe aos adultos, portanto, proporcionar espaços, tempos, materiais e propostas que permitam que as brincadeiras de qualidade aconteçam. Conforme destaca o Manual de Orientação Pedagógica Brinquedos e Brincadeiras de Creches, para "[...] brincar em uma instituição infantil não basta disponibilizar brincadeiras e brinquedos, é preciso planejamento do espaço físico e de ações intencionais que favoreçam um brincar de qualidade" (BRASIL, 2012, p. 11).

Essa pesquisa de Iniciação Científica buscou contemplar o que está previsto nos documentos legais que regem a Educação Infantil, ao propor atividades lúdicas e imaginativas cheias de intencionalidade, que fossem diversificadas e significativas para as crianças.

A pesquisa surgiu em 2011, em uma escola de Educação Infantil situada em um bairro periférico de uma cidade localizada no Oeste Paulista. Durante os momentos de brincadeiras propostas por bolsistas pesquisadores, participantes de um projeto de extensão, constatou-se que havia dificuldades dos alunos, em expressar e de professores, em incentivar e compreender, a imaginação.

A partir desse fato, teve como objetivo estimular e ampliar a imaginação infantil, por meio de brincadeiras, de histórias, de músicas, de atividades teatrais, de brinquedos e artefatos (construídos ou emprestados do laboratório de pesquisa CEPELIJ $^{1}$ ) além de dialogar

\footnotetext{
${ }^{1}$ CEPELIJ: Centro de Estudos e Pesquisa em Educação, Ludicidade,
} Infância e Juventude. É um grupo de estudos e pesquisa que conta constantemente com as crianças e as professoras para que pudessem avançar na compreensão sobre a importância da imaginação e ludicidade.

\section{METODOLOGIA}

De natureza qualitativa, a pesquisa assume o caráter interpretativo dos dados e não quantificáveis.

A metodologia da pesquisa-intervenção melhor se adequou às necessidades da pesquisa, haja vista que consiste em "[...] um plano relacional igualitário que elimina a linha imaginária que separa pesquisador e sujeitos da pesquisa, surjam contribuições para uma transformação da realidade constatada" (SILVA 2012, p. 98 apud CASTRO E BESSET, 2008).

As coletas dos dados foram realizadas por meio de observações, de fotos, de diálogo com os envolvidos na pesquisa, além de anotações no diário de campo. Por qualitativo, Silva (2005, p. 20) considera:

[...] que há uma relação dinâmica entre o mundo real e o sujeito, isto é, um vínculo indissociável entre o mundo objetivo e a subjetividade do sujeito que não pode ser traduzido em números. A interpretação dos fenômenos e a atribuição de significados são básicas no processo de pesquisa qualitativa. Não requer o uso de métodos e técnicas estatísticas. 0 ambiente natural é a fonte direta para coleta de dados e o pesquisador é o instrumento-chave. É descritiva. Os pesquisadores tendem a analisar seus dados indutivamente. 0 processo e seu significado são os focos principais de abordagem.

A pesquisa na escola seguia algumas sequências, embora fosse sempre flexível às necessidades apresentadas pelas falas infantis:

1. Momento de diálogo com as crianças, para ouvi-las, para conhecer o que fizeram durante a semana, se brincaram, etc.;

com alunos de graduação, pós-graduação e professores doutores da FCT/UNESP - Campus de Presidente Prudente. 
2. Apresentação da história;

3. Apresentação e vivência da brincadeira ou brinquedo, sempre relacionada com a história apresentada;

4. Diálogo final: momento para saber se as crianças gostaram da brincadeira, o que foi legal, o que poderia ser mudado, o que gostariam para a próxima aula, entre outros.

Visto que essa pesquisa é realizada com criança, necessário se faz destacar o número do comitê de ética: 13424213800005402.

\section{RESULTADOS}

Em uma das intervenções da pesquisa, contamos uma história sobre uma câmera mágica que fotografava aquilo que as crianças mais gostavam. Posteriormente, demos uma folha de papel com uma câmera fotográfica desenhada para que as crianças expressassem conforme a imaginação, aquilo que mais gostavam na escola. Dos 36 desenhos (total de crianças presentes naquele dia) apresentados, a maior parte expressou a presença das duas pesquisadoras e da professora da sala.

Professoras, pesquisadoras, escola, família possuem um papel fundamental na vida das crianças, visto que por meio de suas ações, práticas e interações, podem-se garantir espaços e tempos para que o brincar aconteça.

Em outro dia da pesquisa apresentamos uma história que deveria ser vivenciada por eles objetivando encontrar o Lipe que havia se perdido na floresta. As crianças precisavam passar por diversos desafios, com a ajuda da imaginação. Colocamos folhas de TNT azul no chão para representar o mar; elásticos postos entre duas cadeiras viraram galhos retorcidos (que para outras crianças eram teias de aranha); cones eram bruxas más que eles precisavam transformar em boazinhas com um abraço (ou fugir porque eram abelhas). Com a história e com diversos objetos que foram (re) significados pelas crianças, estimulou-se amplamente a imaginação.

A fantasia do real foi valorizada e instigada em diversos momentos no decorrer da pesquisa, mas a maior satisfação foi perceber a repercussão - relatada pelas crianças - ao expressarem que brincavam das mesmas histórias em suas casas, ou, quando falavam sobre a intervenção dos encontros anteriores.

Em diversos momentos notamos que, com as brincadeiras ensinadas, as crianças aumentaram seu repertório lúdico e imaginativo. Certo dia, em uma das intervenções da pesquisa, uma das bolsistas observava uma brincadeira de cantinhos $^{2}$, quando se aproximou de Júlia, do Infantil II, que estava com uma boneca na mão, e propôs:

Pesquisadora: - Você gostaria de brincar comigo e com a minha filha?

Júlia: - Professora, não é sua filha, é uma boneca (Diário de campo).

Esse momento explicita a distinção que Júlia havia feito daquilo que era real e daquilo que era fantasia. A brincadeira com o adulto não tinha um significado para ela, assim decidiu deixar claro que aquela não era a filha e sim uma boneca. Muitas crianças brincam com as bolsistas, mas Júlia não quis. Em outro momento, porém, Júlia usou da imaginação ao se sentar perto dos instrumentos musicais da bandinha e dizer para seu par que era baterista. Esse fato expressa que a brincadeira talvez não fosse significativa ou apresentasse para ela, no primeiro momento com a pesquisadora, mas que, no segundo, ao brincar com os pares, ela foi.

Outro aspecto importante para a imaginação e para o repertório lúdico das crianças são os artefatos que se tornam lúdicos quando as crianças trazem para dentro do ambiente escolar. Em outro momento, observamos as crianças brincando com uma bolsa da "Tinker Bell". Ao olhar de forma desatenta, parecia somente uma brincadeira, mas ao observar melhor as crianças, percebemos que usavam da imaginação, pois as meninas brincavam que, quem tocasse na bolsa seria a fada e poderia transformar qualquer objeto da escola.

Além dos objetos e artefatos que as crianças traziam para trocar com os pares na escola, notamos a presença massiva das mídias nas bolsas, lancheiras e materiais escolares. As crianças, portanto, utilizavam a escola para brincar e para expressar a imaginação, principalmente com os pares. A pesquisa possibilitou mais momentos e vivências para as crianças, que puderam, dessa forma, ampliar seu repertório lúdico e imaginativo, encontrando um espaço a mais para brincar (ou, talvez, o único espaço, como foi relatado por uma das crianças).

\footnotetext{
${ }^{2}$ Cantinhos é uma brincadeira onde disponibilizamos para as criaças vários espaços com brinquedos específicos, por exemplo cantinho das bonecas, cantinho da oficina, com carrinhos, cantinho da comida, com utensílios de cozinha, entre outros

${ }^{3}$ Fada de um dos desenhos da Disney
} 


\section{DISCUSSÃO}

Buscou-se por meio do histórico da Sociologia da Infância conhecer um pouco mais dessa teoria que embasa a nossa pesquisa, que tanto valoriza a criança e suas manifestações, como a fantasia do real e a ludicidade tão abordadas nessa pesquisa.

As crianças antecedentes ao século XVII, segundo Ariès (1981), eram concebidas como seres em devir, pessoas em vias de formação, adultos em miniatura, alguém que participava de todas as ações adultas, mas sem nenhuma preocupação com seu desenvolvimento pleno. As concepções de criança e de infância sofreram transformações ao longo do tempo, conforme a época, o contexto, a cultura, entre outros. Construções históricas e sociais - passaram a interessar algumas ciências e disciplinas, como a pedagogia, a psicologia e a pediatria, posteriormente à ênfase e ao surgimento do "sentimento de infância" descrito por Ariès (1981).

Em consonância com esse sentimento, a Sociologia Tradicional, passou a se interessar pelo o universo infantil, não se prendendo apenas às transformações biológicas, mas observando as ações sociais cotidianas. Entretanto, o foco era a socialização da criança, os estudos eram sempre sobre crianças e não com elas, ou seja, uma visão centrada sempre no adulto e em sua fala, desconsiderando as vozes e a participação infantil. Posteriormente, a Sociologia da Educação e a Sociologia da Família se encarregaram de compreender e estudar a criança como aluno; como responsabilidade/interesse familiar; como foco de proteção e de cuidados; como vítima de abusos e maus tratos; como foco das questões de controle/índice de natalidade/mortalidade, entre outros aspectos. Entretanto, o foco ainda era a visão do adulto e não a participação efetiva da criança como ator social.

A partir da década de 1980, na Europa e países de língua inglesa, surge a Sociologia da Infância - teoria que embasa nossa pesquisa. Essa vertente teórica busca superar a visão de criança como ser passivo, como receptor de cultura adulta ou como ser marginalizado, infante, aquele que não fala que não tem voz e nem vez.

Segundo Sarmento (2005), a nova Sociologia engloba todo o processo de revigoração da infância, mesmo com pouco tempo de estudos e lutando com diversos paradoxos que se submetem contra as suas concepções.

Um importante conceito para a Sociologia da Infância é o de Culturas da Infância, que englobam todos os saberes que as crianças trazem consigo. Tais Culturas transportam as marcas dos tempos, exprimem a sociedade nas contradições, nos seus estratos e na complexidade. (SARMENTO, 2002. p. 4).

Sarmento (2003) ao discutir Culturas da Infância, apresenta quatro elementos que denotam as ações das crianças, os chamados Eixos Estruturadores das Culturas da Infância, descritos como: Ludicidade, Interactividade, Reiteração e Fantasia do Real.

A ludicidade é o que a criança tem de mais significativo. As crianças brincam desde os primórdios e contraditoriamente aos pensamentos tradicionais, entre brincar e ter qualquer outro tipo de atividade lhe dito como mais séria e necessária, não possui nenhuma diferença.

A interactividade significa uma forma de a criança relacionar-se socialmente. Para Corsaro (2011, p. 127) refere-se "[...] a coorte ou o grupo de crianças que passa o seu tempo junto quase todos os dias". Brincar, além de prazeroso permite à criança aprender a criar estratégias (para adentrar a brincadeira) ou a burlar regras adultas, permite imaginar, superar medos, conhecer a si e ao outro. Quando significativa, não importa onde estejam ou quanto tempo fique ali.

Ao falar sobre tempo, fazemos a primeira ligação entre os eixos, esclarecendo o que é reiteração. Reiteração é o tempo diferenciado das crianças, elas não acompanham o que é expresso cronologicamente, mas baseiam-se no que lhes é prazeroso. Está aqui a explicação para as crianças brincarem o tempo todo e não acharem cansativo, enquanto os adultos olham e pensam ser absurdo tanto tempo fazendo a mesma coisa.

A fantasia do real refere-se a imaginação da criança. Constitui-se na forma de a criança transpor o mundo real, construindo-o de forma imaginativa, possibilitando à criança as diferentes representações de papéis.

Nossa pesquisa, sem excluir e desmerecer os outros três eixos, foca no eixo fantasia do real. Observamos nas intervenções o quanto as crianças se entregam a tais momentos, basta falarmos que tem um Pirata na escola ou 
que a Cinderela visitou alguém na noite passada, para tudo mudar o sentido.

\section{CONCLUSÕES}

Nesse tópico deixaremos mais claros os mais relevantes resultados da pesquisa: percebemos avançarmos na compreensão sobre a imaginação da criança e suas culturas; enriquecemos a formação da pesquisadora, levantamos questionamentos acerca das culturas infantis que vão requerer ainda mais estudos, e ainda ampliamos o repertório de brincadeiras e atividades lúdicas imaginativas das crianças e dos professores.

É difícil dialogar com um sistema escolar que busca sempre a antecipação de outro ensino, e as vezes deixa de lado a brincadeira para que outros conteúdos sejam abordados, mas temos de entender a importância da infância e a necessidade de pensar e estudar mais sobre crianças.

As crianças são importantes e sem importância; esperase delas que se comportem como crianças, mas são criticadas nas suas infantilidades; é suposto que brinquem absorvidamente quando se lhes diz para brincar, mas não se compreende porque não pensam em parar de brincar quando se thes diz para parar; espera-se que sejam dependentes quando os adultos preferem a dependência, mas deseja-se que tenham um comportamento autônomo; deseja-se que pensem por si próprias, mas são criticadas pelas suas soluções originais para os problemas. (POLLARD, 1985 apud PINTO E SARMENTO, 1997, p.3).

\section{REFERÊNCIAS}

ARIÈS, P. O sentimento da Infância. In: História social da criança e da família. 2 . ed. Rio de Janeiro: LTC, 1981, p.29- 164.

BRASIL. Ministério da Educação. Secretaria de Educação Básica. Diretrizes curriculares nacionais para a educação infantil.Brasília: MEC/SEB, 2010.
BRASIL. Ministério da Educação e do Desporto.

Referencial Curricular Nacional de Educação Infantil: introdução. Brasília: MEC/SEF, 1998. v.1 BRASIL. Manual de orientação pedagógica: brinquedos e brincadeiras de creches. Brasília: MEC, SEB, 2012.

CASTRO, L. R., BESSET, V. L. (orgs.) Pesquisaintervenção na infância e juventude. Rio de Janeiro: Trarepa/FAPERJ, 2008.

CORSARO, W.A. A reprodução Interpretativa no brincar ao faz de conta das crianças. Educação, Sociedade e Culturas, n. 17, p.113-134, fev. 2002. CORSARO, W. Sociologia da infância. Porto Alegre: Artmed, 2011.

LIMA, M. R. C.; LIMA, J. M. A ludicidade como eixo das culturas da infância. Interacções, n.. 27,p. 207-231, 2013. Disponível em: <http://www.eses.pt/interaccoes $>$. MULLER, F.. Entrevista com Willian Corsaro. Educ. Soc., Campinas, v. 28, n. 98, p.271-278, jan. 2007. PINTO, M.; SARMENTO, M.J. (coords.) As crianças: contextos e identidades. Braga: Universidade do Minho, 1997.

SARMENTO, M. J. As culturas da infância nas encruzilhadas da $2^{\circ}$ modernidade. Instituto de Estudos da Criança, Universidade do Minho, Portugal, p.1-22, 2003.

. Gerações e alteridade: interrogações a

partir da Sociologia da Infância. Educação Social, Campinas, v. 26, n. 91, p.361-378, 2005.

Disponivel em: <https://doi.org/10.1590/S010173302005000200003>.

. Imaginário e culturas da infância.

Cadernos de Educação, Pelotas, v. 12, n. 21, p. 51-69, 2003.

SILVA, E. L. Metodologia da pesquisa e elaboração de dissertação. Edna Lúcia da Silva, Estera Muszkat Menezes. 4. ed. rev. atual. Florianópolis: UFSC, 2005.

SIROTA, R. Emergência de uma sociologia da infância: evolução do objeto e do olhar. Cadernos de Pesquisa, São Paulo, n. 112, p.7-31, mar. 2001. http://dx.doi.org/10.1590/S010015742001000100001

Recebido para publicação em 24/08/2016

Revisado em 12/09/2016

Aceito em 26/09/2016 